\title{
Stable Cr isotope compositions of modern silicate mantle reservoirs
}

\author{
LUISE J. WAGNER, MA ${ }^{1}$, ILKA C. KLEINHANNS ${ }^{2}$, \\ STEPHAN KÖNIG ${ }^{1}$, WOLFGANG BACH ${ }^{3}$, OLIVIER \\ ROUXEL $^{4}$, GERHARD WÖRNER ${ }^{5}$ AND RONNY \\ SCHOENBERG $^{1,6}$
}

${ }^{1}$ University of Tuebingen

${ }^{2}$ University of Tuebingen, Geosciences

${ }^{3}$ University of Bremen

${ }^{4}$ Ifremer

${ }^{5}$ University of Göttingen

${ }^{6}$ University of Johannesburg

Presenting Author: wagner.luise@googlemail.com

In Earth's mantle chromium occurs in bivalent $\left(\mathrm{Cr}^{2+}\right)$ and trivalent $\left(\mathrm{Cr}^{3+}\right)$ oxidation states in proportions strongly dependent on the prevailing oxygen fugacity $\left(\mathrm{fO}_{2}\right)$ [1]. The different ionic substitution affinities of $\mathrm{Cr}^{2+}$ and $\mathrm{Cr}^{3+}$ between melt and minerals results in small $\mathrm{Cr}$ stable isotope fractionation during igneous processes such as fractional crystallization and partial melting [2, $3,4]$. However, knowledge of the $\mathrm{Cr}$ isotopic compositions of different mantle domains and potential correlations to mantle $f \mathrm{O}_{2}$ is still very limited.

This study aims at characterizing mafic rocks derived from distinct modern mantle reservoirs in order to investigate potential variations in the $\mathrm{Cr}$ stable isotopic compositions of different magma source regions. Different mantle reservoirs are thereby identified and characterized in radiogenic $\mathrm{Sr}-\mathrm{Nd}-\mathrm{Pb}$ isotopic space.

Our results show significant deviation of some mantle reservoirs from the $\mathrm{Cr}$ isotope composition of the recently defined bulk silicate Earth (BSE) value of $-0.12 \pm 0.06 \%$ in $\delta^{53 / 52} \mathrm{Cr}_{\text {SRM979 }}$ [4]. Influence of various processes on the observed $\mathrm{Cr}$ isotopic fingerprints, such as mixing of different mantle reservoirs, lithospheric interaction, redox cycling, melt differentiation and prevailing oxygen fugacity have yet to be established and will be discussed.

[1] Berry et al. (2006); Amer. Min., 9, 1901-1908. [2] Bonnand et al. (2020); EPSL 532, 116028. [3] Shen et al. (2020); GCA 278, 289-304. [4] Wagner et al. (2021); Chem. Geol. (in press). 